\section{Factors Affecting U.S. Consumer Expenditures of Fresh Flowers and Potted Plants}

\author{
Shuoli Zhao ${ }^{1,5}$, Chengyan Yue ${ }^{2,6,9}$, Mary H. Meyer ${ }^{3,7}$, \\ and Charles R. Hall ${ }^{4,8}$
}

ADDITIONAL INDEX WORDS. floriculture, marketing, age, regional difference

SUMMARY. The floral industry has experienced declining sales in the past few decades, causing many to speculate as to the underlying causes. To identify consumers' spending patterns for fresh flowers and potted plants, we extracted and analyzed quarterly expenditure interview data from the Consumer Expenditure Survey, 1996 to 2013. Our analysis revealed consumption trends over time by age group, and compared the differences in expenditure patterns across states. Additionally, we employed the Heckman two-step model to estimate how flower consumption is affected by sociodemographic characteristics, geographic factors, housing status, and seasonal factors. The estimation results show that the source of declining demand can be attributed to the decrease in both number of flower purchasers and expenditure among purchasers. Many factors including age, marital status, gender, education, income, number of earners in household, population size of the residing city, house type, and number of rooms in the house affect the demand for fresh flowers and potted plants. Given that floral expenditure has been decreasing among consumers under 40 years of age for the past two decades, innovative marketing strategies to target this age cohort are essential for the floral industry's success in the future.

$\mathrm{T}$ he floriculture retailing industry has experienced considerable consolidation since the economic recession in 2008 (Society of American Florists, 2014). National Agricultural Statistics Service of the U.S. Department of Agriculture has been surveying floricultural producers from 15 states each year, and according to their newest release (USDA, $2015 \mathrm{a}$ ), the number of floral producers in 2014 was $4849,21 \%$ lower than the number of producers in 2013 (6115). In fact, this consolidation among growers started years before the economic downturn, largely in response to the increased presence of home centers and mass merchandisers. Moreover, as small-scale growers and

\footnotetext{
${ }^{1}$ Department of Applied Economics, University of Minnesota, 226 Ruttan Hall, 1994 Buford Avenue, Saint Paul, MN 55108

${ }^{2}$ Departments of Horticulture Science and Applied Economics, University of Minnesota, 458 Alderman Hall, 1970 Folwell Avenue, Saint Paul, MN 55108

${ }^{3}$ Department of Horticultural Science, University of Minnesota, 424 Alderman Hall, 1970 Folwell Avenue, Saint Paul, MN 55108

${ }^{4}$ Department of Horticultural Sciences, Texas A\&M University, 202 Horticulture Forest Science Building, College Station, TX 77843

${ }^{5}$ Ph.D. Student

${ }^{6}$ Associate Professor and Bachman Endowed Chair in Horticultural Marketing

${ }^{7}$ Professor and Extension Horticulturist

${ }^{8}$ Professor and Ellison Chair in International Floriculture

${ }^{9}$ Corresponding author. E-mail: yuechy@umn.edu.
}

firms have limited market power, such consolidation activities through mergers and acquisitions will continue to decrease the number of producers (Hall, 2015). From the demand side, decreased profits and sales in the floriculture retailing industry had started well before 2008 (USDA, 2007). Research has shown dampened growth in floriculture sales along with tighter margins, indicating the floral industry was reaching maturity (Behe et al., 2003).

Within all plant categories of floriculture products (e.g., bedding plants, herbaceous perennial plants), fresh cut flowers and potted flowering plants accounted for $\approx 30 \%$ of total sales (USDA, 2015a). The Census of Horticultural Specialties (USDA, 2015b) reported that from 1998 to 2009 , the number of operations for fresh flowers and potted plants dropped by $19 \%$ (from 7905 to 6380), and the annual sales also shrank by $32 \%$ from $\$ 2.19$ to $\$ 1.50$ billion (after adjusting inflation). Five years after the economic recession, the number of operations recovered to 6785 in 2014 with the annual sales of $\$ 1.65$ billion. Therefore, in response to the market recovery and consolidation, and given that more alternative gifting options are increasingly available each year for today's consumers, it is crucial to have a better understanding of the factors that impact consumer purchasing behavior for fresh flowers and potted plants.

Sociodemographic characteristics represent one of the most important factors impacting consumers' decision and choice of floral products. It is reported that $65 \%$ of fresh flower purchasers were female and $96 \%$ of flowers were purchased for female recipients (Society of American Florists, 2005; Yue and Hall, 2010). Meanwhile, preferences for flower cultivar and color also vary by gender (Yue and Behe, 2010) and age group (Yue and Hall, 2010). For example, consumers' interests in buying floral products increase as they get older (Rihn et al., 2011). Other reports have shown that education and income level affect consumers' choice of flower categories and expenditure level on flowers (Yue and Behe, 2008). Lastly, a decrease in family size (Behe et al., 1999) and being married (Rihn et al., 2014) are positively associated with floral consumption.

A previous study has shown that consumers in different geographic regions were not homogeneous in floral purchasing patterns. Yue and Behe (2008) analyzed consumer panel data collected by American Floral Endowment from 1992 to 2005. They found that compared with the U.S. mountain area, consumers in the Pacific and Atlantic U.S. regions were more likely to make purchases from untraditional floral retail channels. Meanwhile, consumers in western and north-central U.S. regions were more likely to choose direct-to-consumer retail and freestanding floral outlets. Those geographically different preferences toward floral retail outlets, in turn, affected the expenditure patterns across regions. However, research investigating how specific residential factors such as population size, urban and metropolitan areas affect flower consumption is limited. One study has shown that sales of bedding and foliage plants were positively associated with local population size (Campbell and Hall, 2010).

The production and sales of floral products are also strongly related to weather conditions, which fluctuate seasonally and annually. Yue and Hall (2010) found that preferences for flower categories had been changing over several years, and, on average, consumers purchased more flowers in the second and fourth quarters of the year. Similarly, Behe et al. (2012) 
concluded that higher maximum air temperatures increased flower sales, with consumers spending substantially more on flowers in the month of May, and the highest sales of flowers during a typical week were on Saturdays. The high sales in May could also be partially due to the Mother's Day holiday.

The economic performance of the floriculture industry is known to be closely related to developments in the housing market, as sales of new houses generate a greater demand for both indoor and outdoor floral products (Khachatryan et al., 2014). However, floricultural products may be affected by different housing types. We are interested in how specific housing characteristics, such as type of house and number of rooms, may influence expenditure on fresh cut flowers and potted plants.

While prior studies in the literature focused on consumer choices of floral outlets, color preferences, variety preferences, and weather influences, no study has, to our knowledge, investigated how the sociodemographic and geographic factors, housing status, yearly and seasonal trend that affect both number of purchasers, and purchasers' level of expenditures on fresh cut flowers and potted plants (hereafter referred to as "flowers"). Moreover, our study uses longitudinal data collected from a representative sample of U.S. consumers, which allows us to identify the consumers' floral expenditure patterns over the past two decades and the expenditure variations by U.S. state.

\section{Materials and methods}

Data. Data used in this study are from the Consumer Expenditure Public-Use Microdata from 1996 to 2013 that were collected by the U.S. Bureau of Labor Statistics (2014). The consumer expenditure (CE) survey is the only Federal survey to provide information on the complete range of expenditures in relation to income and consumer characteristics. The expenditure in CE survey is majorly categorized into food, housing, apparel and services, transportation, health care, entertainment, and other expenditures. It provides a continuous and comprehensive source of data on the buying habits of U.S. consumers, and is widely used in economic research and analysis.
Previous studies have used CE survey data in various fields of consumer research. Lo and Tashiro (2013) used $\mathrm{CE}$ data to examine how personal characteristics affect giving behaviors. Meyer and Sullivan (2013) combined CE data and Current Population Survey data from 2000 to 2011 to investigate changes in consumption and income inequality. Meanwhile, Liu et al. (2013) analyzed household expenditures on food consumed away from home using the 2008 and 2009 CE data; and Kim (2013) adopted CE data from 1986 to 2005 in examining whether precautionary saving motives affect consumer behavior.

We examined floral consumption patterns and trends by looking at 173,711 U.S. households reporting the quarterly interview survey data from 1996 to 2013. The longitudinal data were collected on a quarterly basis. Roughly, 7000 households were interviewed each quarter, and those households were randomly chosen according to stratification criteria determined by the U.S. Census. Each household participant was surveyed for four consecutive quarters, during which consumption information was recorded. In each survey quarter, participants were asked to report their monthly consumption expenditures over the previous 3 months. At the end of the fourth quarter, demographic characteristics and financial profiles were collected. We used the breakdown of these monthly expenditure data for this study.

ECONOMETRIC MODEL. Our primary objective was to analyze the major factors that affect the likelihood a consumer would make a floral purchase in a given month and then the major factors that influence how much was spent. A two-step estimation model based on Heckman $(1976,1979)$ that adjusts for selection bias was adopted for our analysis. The first stage of the analysis employs a probit model to determine the probability of purchasing a good, in this case, flowers, which is called the selection equation. For the second stage, an ordinary least squares (OLS) model is used to estimate the amount of spending from the truncated sample, which is called the outcome equation. Only those respondents who made a purchase are included in the second stage estimation.

A total of 37 independent variables were included in both stages of the Heckman two-step model, including four interactions. There were four groups of explanatory variables: sociodemographic characteristics including age, gender, family size, race, marital status, number of earners, number of young and old household members, number of children, age of children, education, and income level; geographic factors including population size of the residing city and U.S. area, housing status such as number of rooms, type of house; and yearly and seasonal trend variables. Table 1 shows summary statistics for each of the independent variables, along with their respective coding method.

The Heckman two-step model has been widely used to study consumer patterns for various products. Byrne et al. (1996) applied the Heckman model to analyze food-away-fromhome (FAFH) consumption and concluded that FAFH commodity is a necessity for U.S. consumers. Dettmann and Dimitri (2007) used a Heckman two-step model to estimate expenditure patterns of organic vegetables, and found that consumers' education level and household income significantly impact the likelihood of purchase. Rhodes (2010) adopted the Heckman two-step model to study the impact of marketing activities on consumer purchasing behavior on soft drinks. More recently, Bett et al. (2013) employed the Heckman two-step model to estimate consumer preferences for underused chicken products and found age, income, education, and family size to be the most significant factors in determining willingness to pay.

Following Heckman (1979), the first stage selection equation is modeled as:

$$
\begin{aligned}
\operatorname{Pr}\{\text { purchase } & \left.=1 \mid \mathbf{z}_{i}\right\}=\mathbf{z}_{i} \beta+\varepsilon_{i} \\
& =\Phi\left(\mathbf{z}_{i} \beta\right) \quad i=1, \ldots, N
\end{aligned}
$$

where $\varepsilon_{i} \mid z_{i} \sim N(0,1)$

In the selection equation, for all sampled participants, $i=1, \ldots, N$, purchase $=1$ represents those who had purchased flowers. $\mathbf{z}_{i}$ is the vector of consumer demographics and other factors, $\beta$ is the vector of corresponding coefficients, and $\varepsilon_{i}$ is the error term. From the probit estimation, the inverse Mills ratio, $m_{i}$, is computed as ratio of the density function $\phi$ to the cumulative distribution function $\Phi$ of the normal distribution: 
Research Reports

Table 1. Summary statistics of the explanatory variables in the Heckman two-step model used to analyze floral consumption patterns of 173,711 participants in the Consumer Expenditure Survey collected by the U.S. Bureau of Labor Statistics from 1996 to 2013 .

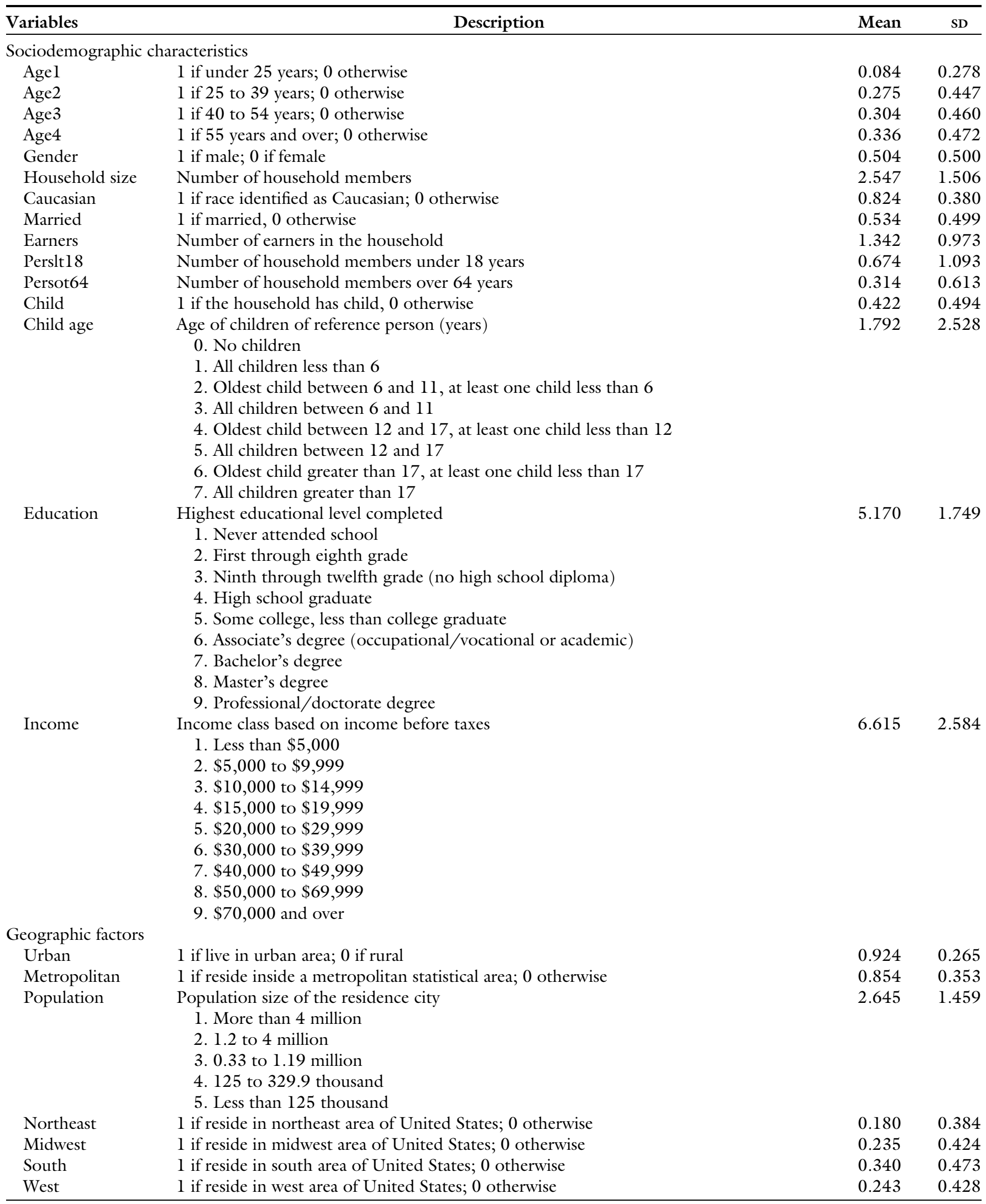


Table 1. (Continued) Summary statistics of the explanatory variables in the Heckman two-step model used to analyze floral consumption patterns of 173,711 participants in the Consumer Expenditure Survey collected by the U.S. Bureau of Labor Statistics from 1996 to 2013.

\begin{tabular}{|c|c|c|c|}
\hline Variables & Description & Mean & SD \\
\hline \multicolumn{4}{|l|}{ Housing status } \\
\hline House owned & 1 if respondent owns his/her house & 0.244 & 0.430 \\
\hline Porch & 1 if respondent's house has porch, terrace, patio, or balcony; 0 otherwise & 0.603 & 0.489 \\
\hline Building type A & 1 if lives in apartment or flat; 0 otherwise & 0.106 & 0.307 \\
\hline Building type $S$ & $\begin{array}{l}1 \text { if lives in single family detached (detached structure with only one primary residence); } \\
0 \text { otherwise }\end{array}$ & 0.638 & 0.481 \\
\hline Vehicle & Number of owned vehicles & 1.896 & 1.540 \\
\hline \multicolumn{4}{|c|}{ Yearly and seasonal trends } \\
\hline Yeartrend $(\mathrm{YT})$ & Trend variable with 1 indicating year 1996 to 18 indicating year 2013 & 8.744 & 4.987 \\
\hline YT $\times$ agel & Interactive trending variable for age group younger than 25 & 0.711 & 2.752 \\
\hline $\mathrm{YT} \times$ age2 & Interactive trending variable for age group from 25 to 39 & 2.303 & 4.572 \\
\hline Q2 & 1 if recorded in April, May, or June; 0 otherwise & 0.242 & 0.428 \\
\hline Q3 & 1 if recorded in July, August, or September; 0 otherwise & 0.244 & 0.430 \\
\hline Q4 & 1 if recorded in October, November, or December; 0 otherwise & 0.250 & 0.432 \\
\hline
\end{tabular}

$$
m_{i}=\frac{\phi\left(\mathbf{z}_{i} \hat{\beta}\right)}{\Phi\left(\mathbf{z}_{i} \hat{\beta}\right)}
$$

The inverse of the Mills ratio is used to correct the sample selection bias in the second stage of estimation. During the second stage, the outcome equation would then be estimated by OLS as follows:

$S_{i}=\mathbf{z}_{i} \gamma+\eta m_{i}+\mu_{i} \quad i=1, \ldots, N$

where $S_{i}$ is the expenditure that consumers made on the purchase of flowers, $\eta$ is the parameter estimate corresponding to the inverse of the Mills ratio, and $\mu_{i}$ is the error term for outcome equation.

For the selection stage, a total of 1,610,966 observations were used for the probit model, among which 126,420 observed floral expenditure data points were used by OLS in the second stage. This means there were $1,484,546$ observations with zero expenditure on flowers. For the nonzero expenditures, the average monthly spending on flower was $\$ 39.45$. All expenditures were adjusted for inflation based on the 1996 price index.

\section{Results and discussion}

There were 1,610,966 CE observations between 1996 and 2013, with almost equal numbers of observations for each year. About 27\% of observations were collected in the first quarter of the year, $24 \%$ in the second quarter, $24 \%$ in the third quarter, and $25 \%$ in the fourth quarter.

About $8 \%$ of the total observations were for consumers under age 25 years; $28 \%$ for consumers who were 25 to 40 years of age; $30 \%$ were for consumers between 40 and 55 years; and the rest of the observations were for consumers 55 years and over. Male and female participants each comprised half of the sample, and married people accounted for $53 \%$ of the sample. The average size of household was 2.5 persons. The mean education level was some college (less than college degree); and the average household income level was $\approx \$ 36,000$. Those sociodemographics of sampled respondents are well representative of the U.S. population.

One of the major uses for flowers is interior home decoration. According to Table 1 , survey respondents reported to have an average number of 5.86 rooms in their homes, and 60\% of houses had a porch, terrace, patio, or balcony. Sixty-three percent were single-family detached homes; $11 \%$ were apartments or flats, and $4 \%$ were multiunit residences. In addition, the average number of vehicles owned by each surveyed household was 1.9.

\section{Floral consumption TRENDS BY} AGE GROUP. The total set of 1,610,966 observations were contributed by 173,711 participants (each of them reported expenditures for multiple months), with 56,148 of them $(32 \%)$ reporting that they made at least one purchase of flowers for the period of time they surveyed (typically less than or equal to 1 year). These 56,148 participants are referred to as "flower purchasers" hereafter. Figure 1 shows the percentage of annual expenditures on flowers by each age group from 1996 to 2013 . According to the figure, one obvious trend is that older people ( 55 years and over) represented a larger percentage of total flower expenditures over time, and the percentage of annual expenditure from consumers younger than 40 years of age was decreasing. In $1996,27 \%$ of total flower expenditure were made by consumers 55 years and over, and this percentage significantly increased to $45 \%$ in 2013 . On the contrary, for flower purchasers between 25 and 39 years of age, percentage of flower expenditures steadily dropped from $36 \%$ in 1996 to only $18 \%$ in 2013 , and the percentage of expenditures made by people under 25 years old also decreased from 6\% in 1996 to $2 \%$ in 2013 . For consumers between 40 and 54 years, their floral expenditures were between $35 \%$ and $40 \%$ and stayed about the same from 1996 to 2013 . 
The reason underlying these expenditure trends could be due to the loss of new customers and young purchasers. Supporting statistics suggested that the overall demand for fresh flowers and floral products decreased from the late 1990s to $2010 \mathrm{~s}$ (USDA, 2015a), particularly among young consumers (Rihn et al., 2011). Previous research has shown that the U.S. wholesale market for flowering potted plants moved into the mature stage of the product life cycle, which resulted in decelerated growth of sales (Behe et al., 2003). Therefore, innovative strategies in both research and development as well as marketing are greatly needed to increase the demand by millennials, and to further enhance the discretionary spending among the existing purchasers.

STATE DIFFERENCES IN FLORAL CONSUMPTION. Geographically, not all states in the United States were sampled, and some state codes were suppressed for confidentiality reasons. According to the U.S. Bureau of Labor Statistics, suppression or recoding of the state variable is necessary in some instances because survey participants could be indirectly identified due to the low number of respondents from their geographic locale. Thus, after adjusting for data suppression and recoding, data could be parsed to account for participants from 41 states. Figure 2 presents a map showing the percentage of flower purchasers in each state, and Fig. 3 shows the average monthly spending among flower purchasers in each state.

As reported in Fig. 2, states in northeast, midwest, and Pacific northwest regions of the United States generally had higher percentages of flower purchasers than southern states. Minnesota had the highest percentage of flower purchasers, $47 \%$, followed by Connecticut, Oregon, Washington, Alaska, Pennsylvania, and Wisconsin, which all had flower purchaser percentages higher than $40 \%$. Comparatively, flower purchasers were fewer than $25 \%$ of the respondents in southern states such as Oklahoma, Louisiana, Georgia, and Florida.

Because not all flower purchasers purchased flowers every month, we estimated their average monthly expenditures by dividing the total flower expenditure by the number of months showing flower purchases. According to Fig. 3, no clear geographic patterns

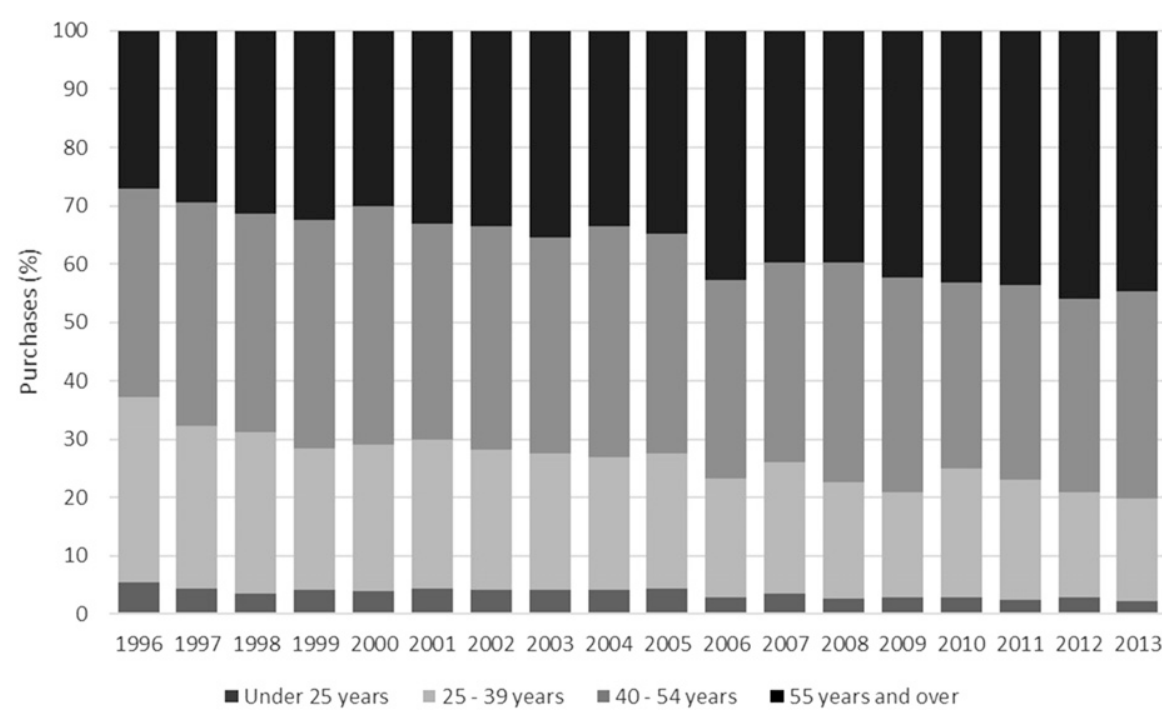

Fig. 1. Transaction percentage of each age cohort making purchases of fresh flower and potted plants according to an analysis of floral consumption patterns of 56,148 flower purchasers in the Consumer Expenditure Survey collected by the U.S. Bureau of Labor Statistics from 1996 to 2013.

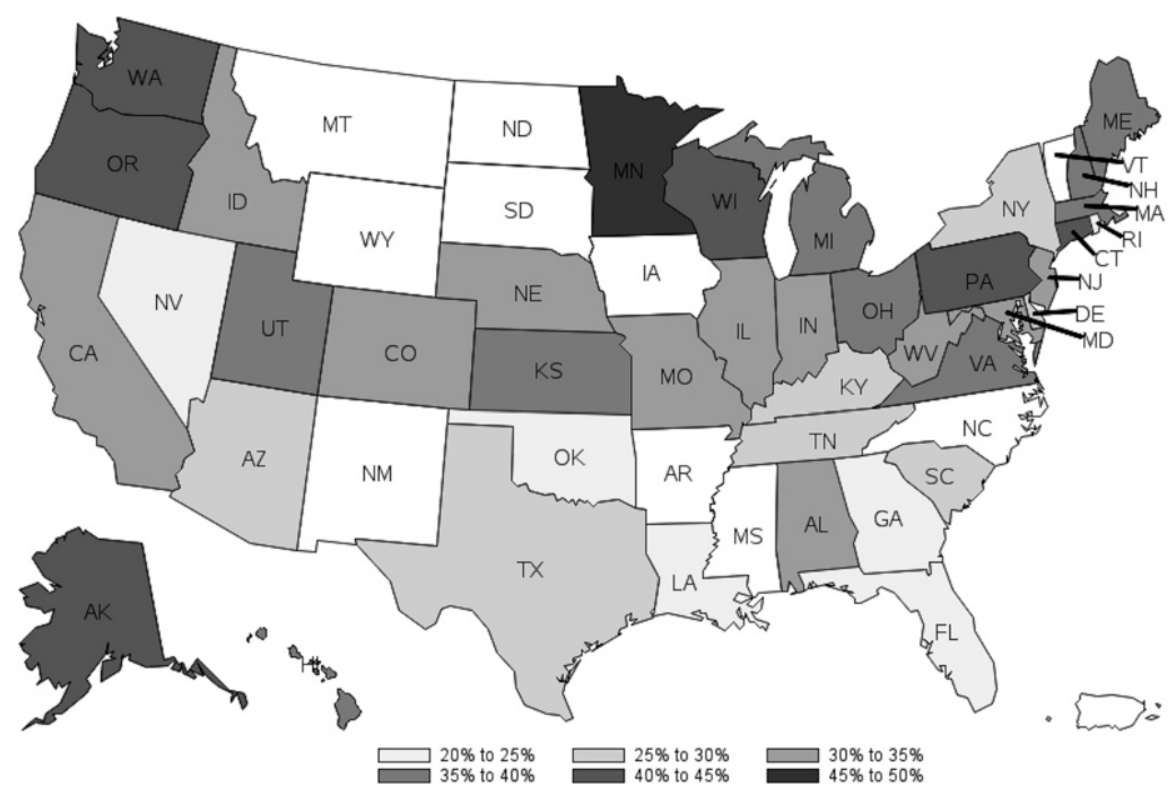

Fig. 2. Map of percentage of population purchasing fresh flowers and potted plants by state according to an analysis of floral consumption patterns of 173,711 participants in the Consumer Expenditure Survey collected by the U.S. Bureau of Labor Statistics from 1996 to 2013.

were found across regions in terms of the monthly expenditure. Idaho, New York, Louisiana, New Jersey, Illinois, and Connecticut were the top states with average monthly expenditures of more than $\$ 50$. The monthly expenditures in most states ranged from $\$ 40$ to $\$ 45$. Flower purchasers from Nebraska, Alabama, Hawaii, Utah, and Oregon spent less than \$35 monthly.

Comparing the percentage of flower purchasers and the monthly expenditures among purchasers, four types of expenditure patterns can be identified. First, for Oklahoma, Nevada, Louisiana, New York, Idaho, and Georgia, the flower purchasers' percentages in those states were relatively lower (less than $30 \%$ ). However, monthly expenditures for flower purchasers in those states were among the highest from $\$ 46$ to $\$ 53$. Second, on the opposite side of the continuum, some states had more flower purchasers, but 


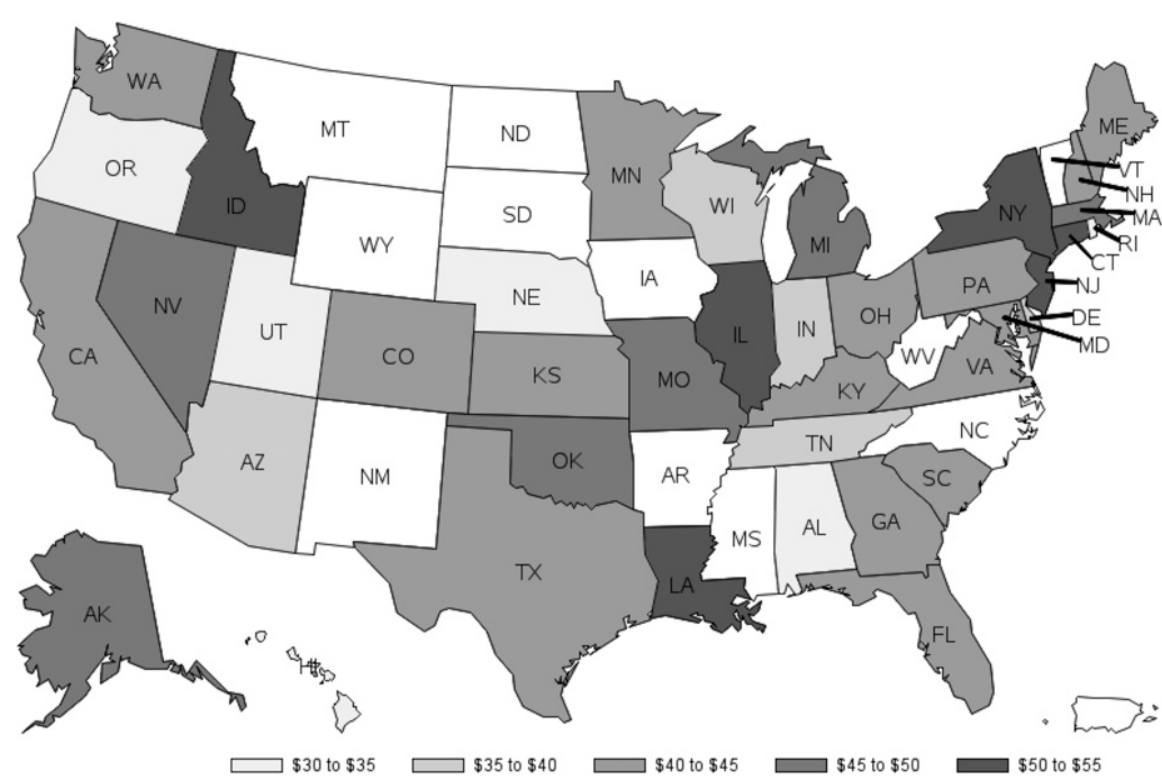

Fig. 3. Map of average spending per month on fresh flowers and potted plants among 56,148 flower purchasers according to an analysis of floral consumption patterns using Consumer Expenditure Survey data collected by the U.S. Bureau of Labor Statistics from 1996 to 2013. Spending information in West Virginia is excluded due to small number of observations.

their monthly expenditures were relatively low. Those states included Oregon, Utah, Hawaii, and Wisconsin. A third group of states represented by Connecticut, Alaska, Michigan, and Massachusetts had both high percentages of purchasers and high monthly expenditures. Lastly, Arizona, Tennessee, and Alabama were characterized by fewer flower purchasers and lower monthly expenditures.

The geographic difference in the percentages of flower purchasers (Fig. 2) can be largely explained by the diverse climate, representing different outdoor environments and landscapes. For example, the lower temperatures in northern states lead to fewer opportunities for outdoor flower and plant enjoyment, but may stimulate more consumers to purchase flowers for indoor use. Meanwhile, consumers in southern states have flowers outside for longer period of time and they could pick flowers from their own landscapes instead of purchasing them. Additionally, because of climate differences, various retailers may thrive in some areas but not others. For example, there could be year-round, convenient street vendors and outdoor markets for flowers in Louisiana, but this cannot exist in colder states such as Minnesota. According to Yue and Behe (2008), visibility of year-round vendors may entice bias. Also the coefficient for the rho statistics is 0.886 , meaning that the unobservables are positively correlated between the two models. Therefore, the unobservables in the selection of purchase stage are positively affecting the level of spending in the second stage. So the Heckman two-step model estimation is needed to correct the selection bias for the data. In addition, the probability values for the likelihood ratio tests were all $<0.001$, indicating a good fit of the model.

S O C I O D E M O G R A P H I C CHARACTERISTICS. For the selection model, all sociodemographic variables were statistically significant at the 0.01 level except for the age group 40 to 54 years. Given that age 55 years and older served as the base level, it means there was no significant difference between consumers who were 40 to 54 years old and consumers who were 55 years and over when deciding whether to buy flowers. However, compared with consumers who were older than 55 years, those younger than 25 years old were less likely to buy flowers, and consumers who were between 25 and 39 years old also had a decreased probability to purchase flowers. In addition, being male, larger household size, having a child and increasing child age all decreased the probability of purchasing flowers. Caucasians and married consumers were more likely to purchase flowers compared with those who were not Caucasians and not married. Increased education and income were positively associated with increased likelihood of purchasing flowers. Meanwhile, more earners in the household, more household members under age 18 and above age 64 years were all positively related to the likelihood of purchasing flowers.

For the outcome model, both Caucasian and married remained statistically significant and positively affected flower expenditures. Consumers with higher levels of education and income also had significant positive effects on expenditures for flowers. In addition, one more earner in a household increased the average household monthly spending on flowers by $\$ 5.85$. Male and younger aged flower purchasers spent significantly less than female and older flower purchasers. Increase in family size and having a child negatively influenced expenditures on flowers. Lastly, it is worth 
Table 2. Heckman two-step estimate results (unstandardized and standardized) of floral consumption using the Consumer Expenditure Survey collected by the U.S. Bureau of Labor Statistics from 1996 to 2013 [n(probit)= 1,610,966; n(OLS)= $126,420]$.

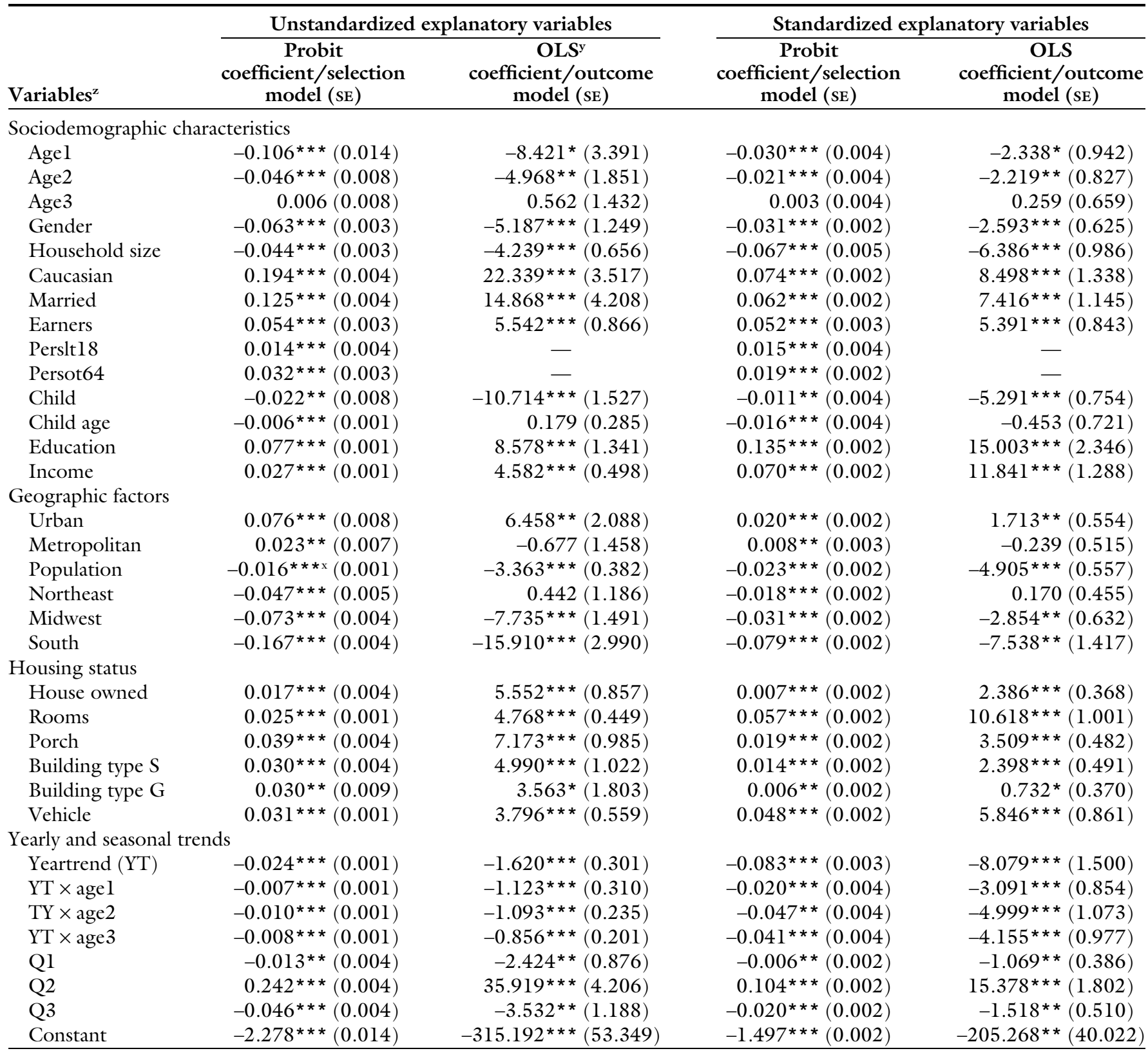

${ }^{2}$ The definition of the variables can be found in Table 1 .

yordinary least squares (OLS) model, only those respondents who made a purchase are included in the second stage estimation.

xPopulation was coded in an inverse order; the significant negative coefficient of population means consumers who live in a city with higher population are more likely to purchase flowers.

${ }^{*}{ }^{* *},{ }^{* *}$ Significant at $0.05,0.01$, and 0.001 levels, respectively.

noting that even though increasing child age, and having more household members under age 18 and above 64 years significantly increased the likelihood of purchasing flowers, these variables did not significantly affect the level of expenditure on flowers.

Comparing the selection and outcome models, we can describe the demographic profile of people who are more likely to purchase flowers, and willing to spend more on flowers.
A typical flower purchaser tends to be an older than 40 years old, Caucasian, married female with high education and income levels, and with more earners but fewer members in the household. Part of the profile is consistent with previous findings, including younger consumers having decreased awareness and interest in floral products compared with older consumers (Rihn et al., 2011), whereas higher income (Yue and Behe, 2010), higher education level (Yue and Hall, 2010), and smaller family size (Rihn et al., 2014) were positive determinants of flower expenditures.

GeOgraphic factors. All of the geographic variables were statistically significant in the selection model. Those consumers who were living in urban areas had a higher likelihood of purchasing flowers compared with those who lived in rural areas. This finding might be because rural residents 
were likely to have flowers from their own home. In addition, consumers who lived in a city with greater population were more likely to purchase flowers compared with consumers who lived in smaller cities. Lastly, people in western region of the United States were more likely to purchase flowers compared with those in other regions. Compared with participants in west, those who lived in the south had the least likelihood to buy flowers, followed by those in midwest and northeast United States, which is consistent with the results shown in Fig. 2.

Compared with the selection model, not all geographic factors were statistically significant in the outcome model. For example, there was not a significant expenditure difference between flower purchasers living in metro and nonmetro areas. Also, relative to western U.S. state consumers, flower purchasers in northeast spent about the same on flowers, while people in southern region generally spent the least amount on flowers. Lastly, urban and population remained significantly positive in the outcome model.

Housing status. Explanatory variables for housing status had consistent signs in both the selection and outcome models. The estimated coefficients for Porch were statistically significantly in both models, meaning that living in a house that has a porch, terrace, patio, or balcony significantly increased both the probability of purchasing flowers and the monthly expenditure on flowers. Having more rooms in a house and owning more vehicles also increased the likelihood of purchasing flowers and the monthly expenditure on flowers. Further, compared with people who rent a house, those who owned their home showed an increased likelihood of purchasing flowers and spent more on flowers. Lastly, people living in a single-family detached house had a higher probability of purchasing flowers and tend to spend more on flowers compared with those who lived in apartments or flats.

YEARLY AND SEASONAL TRENDS. Yeartrend is a continuous variable of the year indicator coded from 1 to 18 to represent each year from 1996 to 2013. According to Table 2, the significant negative coefficients of yeartrend clearly indicated that both the percentage of flower purchasers and the monthly expenditures by flower purchasers were decreasing over time. Further, looking at this consumption trend among the four age groups, the Heckman estimation results were in line with the trending analysis results shown in Fig. 1. Compared with the oldest age group ( 55 years and over), the floral industry lost the most consumers from the age group 25 to 39 years, and flower purchasers in this age group also cut back their spending on flowers at the fastest pace. Moreover, as time went on, consumers aged 40 to 55 years were less likely to purchase flowers. Purchasers under 25 years old also significantly decreased their monthly expenditure on flowers. Similarly in Fig. 1, we see that the transaction percentage accounted for by young purchasers declined from $6 \%$ in 1996 to $2 \%$ in 2013 .

According to the estimates of quarterly variables, we found that there were significantly more flower purchasers in the second quarter, and purchasers also spent significantly more on flowers in the second quarter: April, May, and June. Also, compared with the fourth quarter, people in the first and third quarter were less likely to purchase flowers, and at the same time, purchasers spent slightly less on flowers in those two quarters. Therefore, in the second quarter, when climate is the most suitable for floral growth, consumers are more likely to purchase flowers and they tend to spend more on flowers. The fourth quarter ranked the second probably because there are major holidays (Thanksgiving and Christmas).

Relative importance OF EXPLANATORY VARIABLES. Since the explanatory variables in the Heckman two-step model were not measured in the same units, we further estimated the coefficients of standardized explanatory variables to assess the relative importance of factors influencing the likelihood of floral purchases and floral expenditure (Table 2).

Comparing all explanatory factors, education level had the greatest impact on the likelihood of being a flower purchaser, followed by being in the second quarter of the year, being a Caucasian, income level and being married. For the outcome OLS model, education level and being in the second quarter were still the most important factors that positively affected the flower expenditures among floral purchasers. Number of rooms in a house was the third most important factor, followed by income, being Caucasian, and being married. An interesting finding was that being Caucasian was a more important determinant than income for a person's likelihood of purchasing flowers, while income was a relatively more important factor than being Caucasian in determining how much was spent on flowers.

Yeartrend had the highest negative effects on both the likelihood of purchasing flowers and flower expenditures compared with other variables, meaning that regardless of consumer characteristics, fewer consumers were willing to buy flowers and flower expenditures among purchasers were significantly dampened over the years. Meanwhile, increase in household size, being male, and being younger than 25 years old ranked second to fourth in their effects of decreasing the likelihood of being flower purchasers, and increase in household size, having child, and being male were also estimated to have a negative and significant effect on flower expenditures.

\section{Conclusions}

The overall demand for flowers declined over the past decade (USDA, 2015a). Our study analyzed the trend by using CE Survey data from 1996 to 2013 collected by the U.S. Bureau of Labor Statistics. The estimated results from the Heckman two-step model further identified the source of decreasing demand as 2-fold: one due to the decreasing percentage of flower purchasers, and the second factor was declining monthly expenditures among flower purchasers. Furthermore, our study found that losing younger consumers is one of the major factors that dampened the demand for floral products. Because the percentage of younger flower purchasers decreased at a faster pace than that of older purchasers, and the younger consumers' expenditures on flowers declined more rapidly than that of older consumers. Therefore, to thrive in the increasingly competitive market for discretionary purchases, innovative marketing strategies need to be implemented to develop a value proposition for flowers that will attract younger consumers (Hall, 2010). 
Our study also analyzed how seasonal impacts, housing status, geographic factors, and sociodemographic characteristics affect consumers' likelihood of purchasing flowers and their expenditure on flowers. The results show that many factors including being older, Caucasian, married, female, achieving higher education, and income levels, having more earners but fewer members in the household, living in an urban area with larger population, owning a single-family detached house, having a porch, terrace, patio, or balcony, and multiple rooms in the house all contributed to a higher probability of purchasing and greater expenditures on flowers. While it is a challenge to rejuvenate the demand for flowers and keep flowers as a desired product in the mind of today's consumer, understanding the factors that affect consumers' purchasing behavior is crucial. Thus, given the rapidly changing business environment, floral businesses should have the knowledge of their respective market characteristics, and an accurate assessment of consumers' changing behaviors based on different marketing mix factors, especially when entering a new floral market.

\section{Literature cited}

Behe, B.K., K.L. Getter, and C. Yue. 2012. Should you blame the weather? The influence of weather parameters, month, and day of the week on spring herbaceous plant sales in the U.S. midwest. HortScience 47:71-73.

Behe, B.K., E.H. Moore, A. Cameron, and F.S. Carter. 2003. Repositioning selected herbaceous perennials as indoor flowering potted plants using perceptual mapping. HortScience 38:460-464.

Behe, B.K., R. Nelson, S. Barton, C. Hall, C.D. Safley, and S. Turner. 1999. Consumer preferences for geranium flower color, leaf variegation, and price. HortScience 34:740-742.

Bett, H.K., K.J. Peters, U.M. Nwankwo, and W. Bokelmann. 2013. Estimating consumer preferences and willingness to pay for the underutilised indigenous chicken products. Food Policy 41:218-225.
Byrne, P.J., O. Capps, and A. Saha. 1996. Analysis of food-away-from-home expenditure patterns for US households, 1982-89. Amer. J. Agr. Econ. 78:614627.

Campbell, B.L. and C.R. Hall. 2010. Effects of pricing influences and selling characteristics on plant sales in the green industry. HortScience 45:575-582.

Dettmann, R.L. and C. Dimitri. 2007. Organic consumers: A demographic portrayal of organic vegetable consumption within the United States. European Assn. Agr. Econ. 30:453-463.

Hall, C. 2010. Making cents of green industry economics. HortTechnology 20 : 832-835.

Hall, C. 2015. 2015 state of the industry: Current green industry trends. 5 July 2015. <http://www.greenhousegrower. $\mathrm{com} /$ business-management/2015-stateof-the-industry-current-green-industrytrends/>.

Heckman, J. 1976. The common structure of statistical models of truncation, sample selection and limited dependent variables and a simple estimator for such models. Ann. Econ. Soc. Measurement 5:475-492.

Heckman, J. 1979. Sample selection bias as a specification error. Econometrica 47:153-161.

Khachatryan, H., A.W. Hodges, and S. Steed. 2014. Floriculture crops economic outlook for 2014. 19 July 2016. <https://edis.ifas. ufl.edu/pdffiles/FE/FE94100.pdfs.

Kim, S. 2013. Prudent consumers: New evidence from the Consumer Expenditure Survey. Econ. Model. 33:77-85.

Liu, M., P. Kasteridis, and S.T. Yen. 2013. Who are consuming food away from home and where? Results from the Consumer Expenditure Surveys. Eur. Rev. Agr. Econ. 40:191-213.

Lo, C.P. and S. Tashiro. 2013. Are women more generous than men? Evidence from the US Consumer Expenditure Survey. J. Gend. Stud. 22:282-296.

Meyer, B.D. and J.X. Sullivan. 2013. Consumption and income inequality and the great recession. Amer. Econ. Rev. 103:178183.

Rihn, A.L., C. Yue, B. Behe, and C. Hall. 2011. Generations $X$ and $Y$ attitudes toward fresh flowers as gifts: Implications for the floral industry. HortScience 46:736-743.

Rihn, A.L., C. Yue, C. Hall, and B.K. Behe. 2014. Consumer preferences for longevity information and guarantees on cut flower arrangements. HortScience 49: 769-778.

Rhodes, C. 2010. Demographic variability in U.S. consumer responsiveness to carbonated soft-drink marketing practices. 10 June 2016. <http://ageconsearch. umn.edu/handle/116419>.

Society of American Florists. 2005. Consumer trends on buying flowers. 21 July 2015. <http://www.aboutflowers.com/ about-the-flower-industry/consumertrends.html>.

Society of American Florists. 2014. Floral industry frequently asked questions (FAQs). 21 July 2015. <https://safnow.org/trendsstatistics/floral-industry-facts/>.

U.S. Bureau of Labor Statistics. 2014. Consumer expenditure public-use microdata (CE PUMD). 11 Nov. 2015. <http:// www.bls.gov/cex/pumdhome.htm>.

U.S. Department of Agriculture (USDA). 2007. Floriculture and nursery crops yearbook. U.S. Dept. Agr. Econ. Res. Serv., Ithaca, NY.

U.S. Department of Agriculture (USDA). 2015a. Floriculture crops 2014 summary. 19 June 2015. <http://usda.mannlib. cornell.edu/usda/nass/FlorCrop// 2010s/2014/FlorCrop-06-19-2014. pdf>.

U.S. Department of Agriculture (USDA). $2015 \mathrm{~b}$. Census of horticultural specialties (2014). 30 May 2016. <https://www. agcensus.usda.gov/Publications/2012/ Online_Resources/Census_of_Horticulture_ Specialties/HORTIC.pdfs.

Yue, C. and B.K. Behe. 2008. Estimating US consumers' choice of floral retail outlets. HortScience 43:764-769.

Yue, C. and B.K. Behe. 2010. Consumer color preferences for single-stem cut flowers on calendar holidays and noncalendar occasions. HortScience 45:78-82.

Yue, C. and C. Hall. 2010. Traditional or specialty cut flowers? Estimating US consumers' choice of cut flowers at noncalendar occasions. HortScience 45:382-386. 